\title{
Literatura de turismo sobre o Algarve: O caso dos romances de Rolf Osang
}

\section{Tourist literature about the Algarve: The case of Rolf Osang's fiction}

\author{
João Rodrigues \\ Instituto Politécnico de Beja, Instituto de Literatura Comparada Margarida Losa \\ Centro de Investigação, Desenvolvimento e Inovação em Turismo \\ joao.rodrigues@ipbeja.pt
}

\begin{abstract}
Resumo
Partindo dos estudos em literatura e turismo, nomeadamente do conceito de literatura de turismo (Quinteiro \& Baleiro, 2019), propõe-se, neste artigo, uma leitura dos romances Süßer Mord [Doce Assassínio] (2015) e Algarve-Rache [Vingança Algarvia] (2017), de Rolf Osang, autor alemão de vários guias de viagem sobre Portugal, especialmente sobre o Algarve. Com efeito, o Algarve serve de cenário à ação dos romances supramencionados, que podem ser lidos como guias de viagem literários. Tanto através do narrador como de diversas personagens, são veiculadas, nos romances, múltiplas sugestões de um autor de guias de viagem que conhece de perto a realidade algarvia enquanto membro de uma comunidade internacional de residentes na região e que, no processo de escrita, mantém em vista os interesses dos seus prováveis leitores, nomeadamente (potenciais) visitantes, com quem partilha os recantos de um Algarve "autêntico", além de caracterizar os habitantes locais e refletir sobre a prática turística.
\end{abstract}

Palavras-chave: estudos em literatura e turismo; literatura de turismo; Algarve; Rolf Osang.

\begin{abstract}
Drawing on the theoretical input provided by literature and tourism studies, especially on the concept of tourist literature (Quinteiro \& Baleiro, 2019), this paper aims to focus on the novels Süßer Mord [Sweet Murder] (2015) and Algarve-Rache [Algarve Revenge] (2017), by Rolf Osang, a German author who wrote various guidebooks about Portugal, especially about the Algarve. In fact, the Algarve is also the setting of these novels, which can be read as literary guidebooks. Both the narrator and various characters in the novels convey several travel tips provided by a writer who knows the region very well, as a member of a local community of international residents, and who, in the writing process, bears in mind the specific interests of possible readers, namely (potential) visitors, with whom he shares information on places of interest as well as impressions about the locals, their culture, and tourist practices in the region.
\end{abstract}

Keywords: literature and tourism studies; tourist literature; Algarve; Rolf Osang.

\section{Introdução}

O interesse do povo alemão por Portugal em termos turísticos não constitui um fenómeno recente; com efeito, desde há várias décadas, a Alemanha tem sido um dos países emissores de um número muito significativo de turistas que escolhem Portugal como destino de férias.

Dos Algarves: A Multidisciplinary e-Journal, 37 -2020.

ISBN 2182-5580 @ ESGHT - University of the Algarve, Portugal.

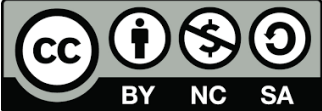

Para citar este artigo: Rodrigues, J. (2020). Literatura de turismo sobre o Algarve: O caso dos romances de Rolf Osang. Dos Algarves: A Multidisciplinary e-Journal, 37, 36-50. DOI: 10.18089/DAMeJ.2020.37.3 


\section{J. Rodrigues}

Os dados disponibilizados pelas entidades oficiais são reveladores da importância deste mercado no contexto português; por exemplo, em 2019, a Alemanha foi o $2 .^{\circ}$ maior mercado da procura externa para Portugal, tendo em consideração o indicador "dormidas" (com uma quota de 12,0\% e 5,9 milhões de dormidas), e o $4 .^{\circ}$ mercado se se tiver como referência o indicador "hóspedes" (com uma quota de 9,3\% e 1,5 milhões de hóspedes) (Turismo de Portugal, 2020: 22-24).

No caso do Algarve, região em foco no presente estudo, há ainda que realçar a existência de uma comunidade de expressão alemã com uma dimensão calculada entre os seis mil e os dez mil residentes, segundo estimativa do cônsul honorário da República Federal da Alemanha em Lagos (Gorzelniak, 2017), comunidade essa que se destaca, a par das de outras nacionalidades, por uma visibilidade notória na região. Além de vários eventos e espaços ligados à cultura alemã, como, por exemplo, o conhecido Oktoberfest e o mercado de Natal realizados anualmente no Vila Vita Biergarten, em Porches, no concelho de Lagoa, é de sublinhar, a este propósito, a existência, há mais de três décadas, da revista mensal Entdecken Sie Algarve [Descubra o Algarve], especificamente direcionada para o público de expressão alemã.

Certamente não alheio a este contexto afigura-se um fenómeno digno de especial atenção e notado pela imprensa alemã (por exemplo, Schmitz, 2019a, 2019b, 2019c) - refirome à publicação, nos últimos anos, de um assinalável número de romances policiais de autores alemães que têm como pano de fundo destinos turísticos populares em Portugal. A título de exemplo, destaquem-se, sobre Lisboa, não só os romances de Luís Sellano, pseudónimo de Oliver Kern, mas também a série de romances intitulada Im Schatten des Santa Justa [À Sombra do Elevador de Santa Justa], de Randolph Kroening. Sobre o Porto, considerem-se as obras de Mário Lima, pseudónimo de Manfred Lührs (vide Oliveira, 2018).

Tal como Lisboa e o Porto, também o Algarve tem, nos últimos anos, merecido a atenção de diversos autores alemães que residem na região ou, pelo menos, nela passam (ou passaram) grande parte do seu tempo. Destaque-se, da autoria de Gil Ribeiro, pseudónimo de Holger Karsten Schmidt, os romances Lost in Fuseta. Ein Portugal-Krimi [Lost in Fuseta. Um Policial em Portugal] (2017), Lost in Fuseta. Spur der Schatten [Pegadas das Sombras] (2018) e Lost in Fuseta. Weiße Fracht [Carga Branca] (2019) (vide Oliveira, 2019). São de referir, igualmente, os romances Mord an der Algarve [Assassínio no Algarve] (2018) e Letzte Spur Algarve [Último Indício Algarve] (2019), de Carolina Conrad, pseudónimo de Bettina von Haskamp, uma jornalista residente na zona de Alcoutim (vide Vilas-Boas, 2020). É ainda de salientar que tanto Gil Ribeiro como Carolina Conrad têm já agendada, para o ano de 2020, a publicação de novos romances policiais cuja ação se centra no Algarve.

Este fenómeno editorial, aparentemente por esgotar, denota um incontornável interesse literário por Portugal, fazendo lembrar, nas palavras de Teresa Martins de Oliveira (2018), "os textos novecentistas e a sua demanda do excêntrico na atmosfera meridional". Enquadram-se, igualmente, neste contexto os dois romances policiais do autor alemão Rolf Osang, nos quais o presente estudo se concentrará, a saber, Süßer Mord [Doce Assassínio] (2015) e Algarve-Rache [Vingança Algarvia] (2017), ${ }^{1}$ ambos dados à estampa pela editora Emons, especializada na publicação de guias de viagem e, sobretudo, como se pode ler no

\footnotetext{
${ }^{1}$ As citações dos textos de Rolf Osang serão apresentadas em português (em tradução minha). No caso dos romances Süßer Mord e Algarve-Rache serão usadas, respetivamente, as siglas SM e AR, seguidas dos números das páginas correspondentes no texto original.
} 
Dos Algarves: A Multidisciplinary e-Journal, 37 - 2020 próprio sítio Web da editora, de Regionalkrimis [romances policiais regionais], não só sobre múltiplas zonas da Alemanha, mas também sobre outros locais de interesse para o público alemão. Até ao momento, os romances disponíveis na supramencionada editora sobre a região mais meridional de Portugal são, precisamente, os dois romances policiais de Rolf Osang.

Nascido em 1949, na zona da Floresta Negra, na Alemanha, Rolf Osang estudou Publicidade e Marketing em Munique, bem como Filosofia em Zurique. A par da sua experiência editorial, há a registar o facto de ter fundado uma agência de publicidade. Viveu em cidades como Estugarda e Londres e residiu, durante mais de quinze anos, em Portugal, país acerca do qual escreveu vários guias de viagem, nomeadamente sobre Lisboa, o Norte do país, os Açores e, principalmente, sobre o Algarve (por exemplo, Osang, 2018; Osang \& Maeritz, 2018). Ao longo de vários anos, publicou ainda, na revista Entdecken Sie Algarve, numerosos artigos, principalmente sobre vinhos e locais a visitar em Portugal. Osang tornouse igualmente conhecido pelo seu amor às artes e por um notável dinamismo na cena cultural algarvia, tendo sido responsável pela organização de diversos mercados, concertos, tertúlias e exposições. Ao seu nome ficaram indelevelmente associadas iniciativas como o projeto Porca Preta, uma aldeia artística localizada no coração da Serra de Monchique, área geográfica que merece especial destaque em ambos os romances, ou ainda a criação de espaços como a galeria Arte Algarve, alojada no edifício da antiga adega cooperativa em Lagoa, e o espaço GaleRio, perto da foz do Rio Arade (Santos, 2004; Osang 2005a; Gaspar, 2015: 30). As múltiplas reações de pesar registadas, em maio de 2018, aquando do falecimento de Rolf Osang, vítima de doença prolongada, ilustram o amplo reconhecimento do papel relevante desempenhado pelo autor no panorama cultural do Algarve (por exemplo, Donn, 2018; s.a., 2018).

O primeiro contacto com os romances de Osang, bem como com outros textos dos autores supramencionados, permite-nos detetar, de imediato, a evidente ligação que neles é promovida entre a literatura e o turismo. Por esse motivo, pareceu-me pertinente a escolha do tema do presente estudo, não só no âmbito do simpósio em que foi inicialmente apresentado, mas também no contexto de um eventual trabalho de investigação mais alargado. É igualmente de notar que, até à data, muitos destes textos permanecem por explorar no mundo académico, muito embora seja de relembrar a publicação, na enciclopédia digital Ulyssei@s, de verbetes relativos a alguns dos autores referidos, nomeadamente, Mário Lima (Oliveira, 2018), Gil Ribeiro (Oliveira, 2019) e Carolina Conrad (Vilas-Boas, 2020).

\section{A literatura de turismo e os romances de Rolf Osang}

Como ponto de partida para a leitura dos romances de Osang, afigurou-se-me como profícuo o recurso ao manancial teórico dos estudos em literatura e turismo, nos quais, como destacam Sílvia Quinteiro e Rita Baleiro (2019), tem particular destaque a literatura de turismo. Recorde-se que, alicerçada numa ponte privilegiada entre os estudos literários e os estudos de turismo, a literatura de turismo inclui textos de vários géneros que:

(i) têm a capacidade de acrescentar valor turístico a um lugar e, por esse motivo, promovem uma prática turística (referindo ou sugerindo lugares e motivando por essa via uma viagem ou a construção de um itinerário turístico); 
(ii) promovem a reflexão sobre o turismo e a atividade turística, em geral, bem como sobre os atores nela envolvidos (turistas e viajantes) e nela implicados, por vezes, involuntariamente (os habitantes locais dos destinos turísticos);

(iii) retratam práticas de turismo, em geral, e de turismo literário, em particular.

(Quinteiro \& Baleiro, 2019: 24)

Como as autoras fazem notar, os exemplos de literatura de turismo podem evidenciar um ou mais traços distintivos de entre os enunciados (ibidem). Tomando este conjunto de características como fio condutor da análise proposta, podemos constatar que este é o caso dos romances de Rolf Osang, nos quais, como será demonstrado, (i) é evidente a promoção da prática turística através da recomendação de locais a visitar, (ii) se reflete sobre o turismo na região e se caracterizam tanto os algarvios como os turistas/viajantes e os membros da comunidade internacional residente no Algarve e, em última análise, (iii) são representadas práticas de turismo indiscutivelmente ligadas à luz da experiência do próprio autor. Face à existência de evidentes pontos de contacto entre estas três dimensões, as linhas de leitura delas decorrentes serão tratadas de forma integrada.

Ainda que de modo necessariamente sucinto, importa, neste contexto, fazer uma referência à diegese dos romances que integram o corpus de análise, Süßer Mord e AlgarveRache, entre os quais se estabelece uma continuidade patente, sobretudo, nas personagens que neles há em comum. Nestes textos é narrado o regresso da protagonista, Lisa, uma jovem de 27 anos residente em Berlim, a Portugal, de onde fora subitamente levada aos quatro anos de idade pela mãe - Joana. No âmbito desse regresso, Lisa procura perceber os motivos da fuga da mãe há mais de duas décadas e, nesse processo, acaba por descobrir as suas raízes e confirmar a identidade do seu próprio pai - Jorge -, com quem Joana tivera uma relação e de quem se afastara súbita e inexplicavelmente. São o retorno de Lisa à sua terra natal e o (re)encontro com o pai que servem, em larga medida, de pretexto para a representação literária de Portugal, mais concretamente do Algarve, nas obras em apreço.

Em ambos os romances, Lisa depara com crimes que tenta deslindar: em Süßer Mord, a protagonista vê a sua vida em risco na Serra de Monchique, num incêndio de origem criminosa encomendado por um empresário milionário que planeia construir, no Barlavento algarvio, o maior campo de golfe da Europa; por seu turno, em Algarve-Rache, cerca de um ano após o seu regresso a Portugal, Lisa é contactada por uma mulher que lhe encomenda a organização de uma exposição no pitoresco Castelo de Ferragudo, exposição essa que faz, na verdade, parte de uma agenda de vingança.

Na resolução dos mistérios em que se vê envolvida, e na tentativa de reposição da ordem interrompida, como é típico de romances policiais (Neves, 2009; Reis, 2018: 464-470), Lisa conta com a colaboração de adjuvantes, neste caso, de personagens que, embora tenham estado ausentes do país por períodos longos, se encontram ligadas ao Algarve. Refiram-se, por exemplo, Pablo (sobretudo em Süßer Mord) e Moa (em Algarve-Rache), que, além de auxiliarem a protagonista na busca e na descodificação de pistas, com ela partilham factos e curiosidades sobre a região (e o país), os seus habitantes e a respetiva cultura, desempenhando, em vários passos, o papel de guias turísticos, tal como é sugerido explicitamente pelo narrador ou nos próprios diálogos entre as personagens (por exemplo, sobre Pablo, veja-se SM: 95 e AR: 115; sobre Moa, AR: 58, 236, 244).

Tomando esta ideia como ponto de partida para a análise, e recuperando o primeiro traço distintivo da literatura de turismo, acima mencionado, saliente-se que, tal como 
Dos Algarves: A Multidisciplinary e-Journal, $37-2020$ sublinha Anabela Gaspar (2015: 31), editora da revista Entdecken Sie Algarve, estes romances podem ser lidos como Reiseführer [guias de viagem]. Com efeito, o leitor é conduzido por diversos lugares a visitar no Algarve, muitos deles fora dos tradicionais circuitos do turismo de massas, como será explorado adiante, evidenciando-se claramente nesses percursos a voz de um autor com vasta experiência de escrita de guias de viagem.

Como Osang admite em entrevista, a perspetiva veiculada nos romances não pode, naturalmente, ser desligada do seu próprio percurso biográfico (ibidem). Além da notória coincidência entre nomes de personagens dos romances e de pessoas que terão integrado os círculos de contactos do autor, ${ }^{2}$ afigura-se como especialmente relevante o facto de Osang ser um cidadão alemão que "descodificou”, ele próprio, Portugal (e, particularmente, o Algarve) e que sobre ele escreveu, em romances até à data publicados apenas em alemão, para leitores oriundos de um país e de uma cultura que ele tão bem conhece. Não é, pois, possível ignorar a função de mediador intercultural que Osang assume nos romances, função essa que replica, ou aliás, intensifica, um traço distintivo do guia de viagem, género com que o autor se encontra particularmente familiarizado. Afinal, a qualquer guia de viagem subjaz, por definição, um exercício de "filtragem interpretativa" que resulta no condicionamento da maneira como o leitor dos guias perceciona a cultura neles representada (Cordeiro, 2010: 9293).

A propósito da aproximação dos romances ao género do guia de viagem, não se pode deixar de referir a relevância da dimensão paratextual das obras. Repare-se, por exemplo, nos títulos e subtítulos - Süßer Mord. Algarve Krimi e Algarve-Rache. Kriminalroman. Em ambos os casos, é de assinalar não só a identificação genológica dos textos, mas, sobretudo, o facto de os romances policiais serem explicitamente apresentados como referentes ao Algarve (seja no título, seja no subtítulo), o que, à luz do fenómeno editorial de que aqui se vem dando conta, denota uma intenção inequívoca de captar a atenção de leitores com um interesse específico na região. As recensões disponíveis (nomeadamente, no sítio Web da Amazon alemã) remetem para esta mesma ideia, na medida em que, nas várias críticas - tanto positivas como negativas -, a aquisição e/ou a leitura do livro são associadas a uma estada na região. ${ }^{3}$

Além disso, a inclusão, no início do primeiro romance, de um mapa com a referência a diversos pontos de interesse no Algarve, estratégia a que vários dos autores alemães acima mencionados recorrem, posiciona igualmente o leitor (e as suas expectativas) entre os dois géneros textuais referidos. Reforça-se, deste modo, a ideia de que a dimensão ficcional dos textos se inscreve num universo de referência real para o qual é, explícita e recorrentemente, chamada a atenção do leitor.

\footnotetext{
${ }^{2}$ Apesar de não se pretender, de modo algum, reduzir a leitura dos textos a um exercício de índole biografista, refiram-se, em jeito de nota, dois exemplos: Antonieta, nome da figura secundária que, nos romances, trabalha na casa de Jorge e é recorrentemente elogiada pelos seus cozinhados, é igualmente o nome de uma das "vizinhas" do espaço Porca Preta, conhecida pelos seus petiscos caseiros, muito apreciados pelos visitantes daquele local (por exemplo, Osang, 2005a; Tavares, 2018); Pablo, nome de outra personagem secundária dos romances e um dos adjuvantes da protagonista, é também o nome do assistente que colaborou com Rolf Osang na abertura da galeria Arte Algarve, em Lagoa (Tavares, 2018). Na verdade, tal associação é confirmada em Süßer Mord (veja-se, a este propósito, SM: 93-95).

3 https://www.amazon.de/S\%C3\%BC\%C3\%9Fer-Mord-Algarve-Krimi-Osang-

ebook/dp/BooQV8OOFM/ref=dp_kinw_strp_1>; <https://www.amazon.de/Algarve-Rache-Rolf-Osangebook/dp/Bo6XCPT9ZB/ref=dp_kinw_strp_1. Consultados em 05.03.2020.
} 
De facto, nos dois romances, são múltiplas as recomendações de lugares a visitar - não só cidades associadas aos circuitos mais tradicionais, tais como Lagos, Albufeira, Tavira e Faro, mas também vários lugares mais recônditos, afastados dos circuitos do turismo de massas, tanto no profundo Algarve rural como no Algarve litoral. As informações sobre esses lugares são geralmente veiculadas a propósito de deslocações das personagens, principalmente da protagonista, no âmbito da procura de pistas sobre os mistérios que almeja deslindar. Vejamos, por exemplo, um trecho sobre a passagem de Lisa por Faro: ao longo de várias páginas, o leitor acompanha a protagonista, que recebe de Pablo, in loco, múltiplas informações sobre a cidade e a sua história:

\footnotetext{
-Como futura algarvia tens de saber que apenas com a reconquista de Faro é que os Cristãos quebraram definitivamente o domínio dos Mouros no Algarve. Isso foi no ano de 1249. Numa das portas da cidade há dois grandes painéis de azulejos pintados à mão que representam esse marco histórico. Iremos vê-los daqui a nada. - Pablo adorava fazer de guia turístico e não deixou passar esta oportunidade em branco.

Caminhando para Sul, passaram primeiro por um grande cemitério e depois por uns prédios enormes até que, umas centenas de metros adiante, chegaram ao centro da cidade, onde as lojas nasciam umas a seguir às outras e havia gente sentada nos inúmeros cafés a conversar com entusiasmo. Apesar da confusão, sentia-se no ar a descontração portuguesa, que se tornava visível por algo em particular: a ausência de stress.

- Vês aqueles barcos lá à frente [...] e, mesmo ao lado, aquele pequeno jardim? Chama-se Jardim Manuel Bivar, e a Cidade Velha começa mesmo ali ao lado. (AR: 115)
}

Repare-se como este excerto de cariz ilustrativo se reveste de uma índole informativa patente na partilha de dados geralmente incluídos num guia de viagens. Na verdade, tanto aqui como em vários outros passos textuais, em que o uso abundante de deíticos não passa despercebido, o leitor é integrado no percurso de uma visita guiada. A este propósito, importa referir que esta estratégia discursiva não é unanimemente aceite, pois, como se comprova em diversas recensões disponíveis na plataforma da Amazon, anteriormente indicada, são várias as vozes que a consideram artificial e um elemento que torna o texto mais pobre. Não obstante, podemos indubitavelmente afirmar que os romances encerram em si a função de instrumento auxiliar na descoberta autónoma dos lugares pelo leitor.

Neste contexto, não podemos deixar de sublinhar o modo como o convite dirigido ao leitor para visitar lugares de interesse se entretece com a intriga dos romances. Por exemplo, no romance Algarve-Rache, a protagonista procura pistas sobre vários crimes ocorridos através da observação de fotografias que lhe são entregues para a organização de uma exposição, fotografias essas que se centram na imagem de homens oriundos de vários lugares do Algarve e que, como Lisa vem a descobrir, são vítimas de hediondos ataques relacionados com crimes de abuso sexual que eles próprios terão cometido no passado. Com o auxílio dos seus adjuvantes, Lisa procura descodificar o local onde as fotografias foram tiradas para obter mais informações sobre as vítimas e a motivação dos ataques, o que a conduz a lugares de preciosa beleza na região, como, por exemplo, a ilha da Culatra, Alcoutim, a ria de Alvor, entre outros.

Recria-se, assim, através deste exercício de identificação de "recantos" do Algarve, um processo intrínseco à utilização de guias de viagem. Com efeito, a consulta desses textos resulta, não raro, na busca da versão "real" de locais neles pictoricamente reproduzidos, com base em indicações práticas de acesso, indicações essas que, nos romances de Osang, são 
por vezes tão pormenorizadas que legitimam a aproximação de vários segmentos narrativos ao que poderíamos considerar o guião de um sistema de navegação por satélite, vulgo GPS, tal como exemplificado no excerto abaixo transcrito:

\begin{abstract}
Junto ao mais antigo hotel de golfe do Algarve, o Penina Resort, [Pablo e Lisa] entraram na $\mathrm{N} 125$ e viraram à direita para Lagos, andaram sete quilómetros e então, junto à entrada de Odiáxere, viraram à esquerda em direção a Vale de Lama. A casa na esquina da N125 era um grande café desportivo, onde havia homens ao sol a beber cerveja, a fumar e a discutir, certamente sobre futebol.

Pablo conduziu [... ] uns dois quilómetros por uma estrada estreita em direção ao mar até que viram a linha do caminho de ferro do lado esquerdo. A linha ligava Lagos a Faro e, com uma mudança em Tunes, também a Lisboa; no entanto, eram já poucas as locomotivas a gasóleo que ali circulavam diariamente, aos solavancos, com uma ou duas carruagens atreladas. Infelizmente, cada vez menos passageiros aproveitavam da janela do comboio a vista para os jardins, quintais, para as hortas e zonas industriais, ou seja, para a vida autêntica do Algarve. Já quase ninguém passava pelos laranjais, pelas salinas brilhantes ao sol, pelas dunas douradas ou pelas lagoas azuis. Era num passeio de comboio que a mais bela costa da Europa se mostrava nos seus melhores ângulos. (AR: 101-102)
\end{abstract}

A precisão das coordenadas evidenciadas na primeira parte deste excerto coloca em destaque o perfil utilitário que caracteriza muitos dos passos dos romances de Osang, que parecem corresponder, em vários casos, às secções típicas de um guia de viagem, como "O que visitar", "Como lá chegar" ou, até mesmo, "Onde comer", conforme atestam as abundantes referências a cafés e restaurantes de diversas localidades. ${ }^{4}$

O passo supratranscrito ilustra ainda o tipo de itinerário turístico promovido nos romances de Osang, aquele que, longe do turismo de massas, se concretiza na busca de recantos "autênticos", como os quintais aqui referidos, e na adequação a um ritmo lento, ou melhor, desacelerado, que parece aliás encontrar-se naturalmente inscrito na paisagem da região. Sobre o passeio de Lisa e Pablo, perto do caminho de ferro em Faro, podemos ainda ler: "Ouviu-se um sinal de aviso bem alto, pois algumas pessoas caminhavam tranquilamente pelas linhas e demoravam a deixar o comboio passar. O maquinista teve de esperar. Talvez até o tenha feito com prazer, pois a vista do caminho de ferro sobre a resplandecente Ria Formosa, que se espraiava diante de Faro, era maravilhosa" (AR: 115). O ritmo lento, patente na sugestiva e paradoxal imagem de um comboio que reduz a velocidade para se adequar ao passo dos transeuntes e dar lugar ao exercício contemplativo de uma beleza que se impõe naturalmente, constitui, de facto, um leitmotiv nuclear na construção da representação do Algarve nos romances de Osang. Para esta ideia concorre igualmente a reiterada menção de cenários de beleza sedutora em que diversos figurantes parecem imersos na contemplação da paisagem e a aguardar a passagem do tempo (por exemplo, SM: 168; AR: 164). Tal "dormência" é, inclusive, frequentemente estendida a elementos da paisagem em si, como ilustrado num dos trechos sobre Ferragudo: "O Rio Arade fazia uma curva um pouco para dentro mesmo antes da povoação, criando uma espécie de bacia portuária natural. Na água baloiçavam três dúzias de coloridos barcos de pescadores que pareciam estar a descansar da

\footnotetext{
4 A título de exemplo, leia-se o seguinte passo de Algarve-Rache, em que Lisa e Moa se deslocam a Albufeira: "Agora, antes de mais, é hora de tomar um café e comer um bolo. Conheço ali um sítio bem simpático, a poucos passos daqui - propôs Moa. [...] Pouco depois estavam sentadas na Rua Latino Coelho, na esplanada do restaurante "O Penedo». A vista [...] sobre a praia da cidade, a Praia do Pacheco, que se espraiava mesmo ali por baixo, serviu de compensação pelo desagradável encontro com a Senhora Palma." (AR: 238).
} 


\section{J. Rodrigues}

última viagem. Com a baixa-mar ficavam deitados de lado, como se estivessem a passar pelas brasas." (AR: 219).

Além disso, há que notar que este ritmo lento adquire notória relevância quando lido enquanto parte de uma relação dicotómica que, nos romances de Osang, se estabelece entre o Algarve e uma "outra Europa", modernizada, como a Alemanha onde Lisa crescera e da qual se sente cada vez mais distante: "Lisa vivia há meses no Algarve e, naquele momento, tal como em tantos outros, tornava-se-lhe claro que aqui não havia pressa. Pelo menos não naquela forma avassaladora que ela conhecia da sua terra nórdica, que entretanto deixara de ser a sua terra." (AR: 162). A dicotomia em apreço pode ser lida como uma dinâmica distintiva dos textos de viagens contemporâneos, nos quais se verifica, não raro, uma representação dos destinos turísticos como palcos para a projeção de configurações paradisíacas e idílicas de espaços em que se materializam o sonho e o desejo de evasão do quotidiano associado aos locais de origem (Cordeiro, 2013: 145).

Nos textos de Osang, a perceção de um tempo lento torna-se especialmente visível na descrição de diversos lugares mais remotos, onde se concretiza a imagem de um país adormecido ou parado no tempo. Na verdade, num estudo sobre as representações de Portugal na literatura turística alemã, Maria João Cordeiro (2010) aponta três categorias temáticas fundamentais, nomeadamente "Paraíso", "Vivência Meridional" e "Tempo Parado", identificando esta última como a de maior peso nos guias de viagem e artigos de imprensa por si analisados. Como salienta, Portugal é frequentemente caracterizado como um "país exoticamente anacrónico [...], onde o fluir temporal parece ter sido suspenso" (idem: 154). Tal suspensão não é, porém, entendida de modo negativo, mas "contribui para a atractividade de um exotismo idealizado do país. Com efeito, a estagnação e a desertificação das aldeias são transformadas discursivamente em locais mágicos que exalam o charme irresistível do anacronismo, subsistindo como museus vivos [...]" (ibidem). Este parece ser também o caso nos romances de Osang: por exemplo, em Algarve-Rache, a fotografia que serve de pretexto para a visita de Lisa e Moa a Alcoutim é descrita da seguinte forma:

\footnotetext{
A fotografia mostrava uma paisagem despovoada [...]. Um homem [...] fazia festas na cabeça de um burro. [...] Havia mais alguns homens sentados no chão. Pausa para a merenda. Um garrafão de cinco litros de vinho ia passando de mão em mão. Os homens pareciam contentes. [...]

Da fotografia emanava um sossego colossal. [...] Sobreiros isolados erguiam-se como formas solitárias [... ] e acentuavam a aridez e a sensação de abandono, mas também a serenidade interminável desta paisagem quase intocada [...].

-A solidão e os agricultores com o burro fazem-me lembrar os tempos em que o ditador Salazar estava no poder. (AR: 99)
}

Como exemplo de um interior desertificado, que Osang procura incluir nos seus itinerários, a localidade de Alcoutim é caracterizada como uma comunidade em que todos se conhecem e que, esvaziada de jovens, parece votada ao inevitável envelhecimento, mantendo-se à margem da modernidade e imersa num passado que se manifesta nos objetos e nas práticas do quotidiano. A referência, de valor icónico, à presença do burro, elemento aliás recorrente na literatura turística sobre Portugal, pode ser lida como parte do processo de construção da imagem "de um país onde o passado não se tornou um passado-objecto, retirado do contexto da vida diária e colocado cuidadosamente numa redoma, mas se mantém material 
Dos Algarves: A Multidisciplinary e-Journal, $37-2020$ e quotidianamente presente" (Cordeiro, 2010: 154). De facto, são vários os momentos em que, nos romances de Osang, parece ser dada atenção a simples objetos que, aos olhos de Lisa, se afiguram como vestígios de outra era: “- Culatra, ida e volta - disseram Lisa e Pablo quase em uníssono; cada um deixou os dois euros e setenta certos no pratinho de plástico, e recolheram os seus bilhetes destacáveis, que tinham provavelmente sido impressos há trinta anos; pelo menos, assim parecia." (AR: 163).

Neste contexto, torna-se igualmente pertinente referir que, além da categoria "Tempo Parado", também as categorias "Paraíso" e "Vivência Meridional” (Cordeiro, 2010), acima referidas, são indissociáveis da representação do Algarve nos romances de Osang. As numerosas e, muitas vezes, longas descrições encontram-se, na realidade, na base da construção de um Sul paradisíaco, apontado como tendo o melhor clima da Europa (SM: 183; AR: 157) e onde ainda abundam as paisagens virgens - sobretudo na Costa Vicentina, que, pelas suas praias (semi)desertas e monumentais falésias, é várias vezes referida como o mais belo recanto da Europa (por exemplo, AR: 23).

A construção do Algarve como um paraíso assenta, igualmente, na sua configuração como um espaço excecionalmente fértil, onde, tal como numa estufa, tudo parece crescer (AR: 9) e onde os sentidos são permanentemente deleitados - além das sensações visuais, os aromas e os sabores são também amplamente explorados nos romances. Com efeito, a gastronomia, destacada pelas frequentes referências às iguarias, aos temperos e aos ingredientes algarvios, concorre igualmente para essa configuração da região como paradisíaca e meridional por excelência. Também a este nível é evidente a voz do autor de guias de viagem dirigidos ao público alemão, que não só integra nos diálogos pormenores sobre a confeção de especialidades típicas, como a salada de azeitonas e cenoura temperada à moda algarvia ou a cataplana (SM: 41; AR: 22), mas também esclarece dúvidas comuns entre os falantes de língua alemã em torno, por exemplo, do que são "percebes" [sic], desconhecidos para muitos turistas e viajantes (SM: 95; AR: 227). ${ }^{5}$

Recuperando o fio condutor da análise em curso, podemos igualmente afirmar que os romances de Osang, enquanto exemplos de literatura de turismo, além de assentarem na recomendação de espaços diversos, como vimos até aqui, promovem, por um lado, a reflexão em torno dos habitantes locais e, por outro, sobre os visitantes e a comunidade estrangeira residente no Algarve. Lisa surge como exemplo de uma alemã que vem para Portugal, se apaixona pelo país e ali se fixa, convivendo facilmente com os portugueses, também por já ter algum domínio da língua. Tal como as suas deslocações pela região servem de pretexto para a referenciação de pontos de interesse, do mesmo modo os diálogos de Lisa com outras personagens são explicitamente usados para descodificar aspetos culturais relevantes, muitos deles exaustivamente explorados nos guias de viagem sobre Portugal - é o caso dos diálogos sobre o fado, a saudade ou as marcas contemporâneas de um passado tanto longínquo como recente, tal como é evidenciado, por exemplo, pelas referências ao período dos Descobrimentos ou ao período do Estado Novo, respetivamente. Com efeito, muitos dos aspetos da cultura portuguesa são explicados à luz de sínteses históricas,

\footnotetext{
${ }^{5}$ Ao longo dos romances são pontualmente deixadas em língua portuguesa algumas palavras-chave do quotidiano em Portugal, que, pela sua especificidade, se revelam de difícil tradução, tais como "pastelaria" ou "pastel de nata" (AR: 106-107), muitas vezes acompanhadas por breves notas explicativas adaptadas ao leitor alemão, mais uma vez, tal como se de uma secção de "sobrevivência" de um guia de viagem se tratasse: "Para si tinha pedido uma bica, um pequeno café expresso" (AR: 132).
} 
também elas deveras pormenorizadas - a tolerância do povo, por exemplo, é ilustrada à luz da história dos Templários, que, apesar de ferozmente perseguidos em vários países da Europa durante a Idade Média, encontraram em Portugal um porto seguro (AR: 244-245); o orgulho português é frequentemente relacionado com a memória coletiva em torno de uma grandeza do país geralmente associada ao período da expansão marítima (por exemplo, AR: 263); por seu turno, o notório receio de enfrentar as autoridades é visto como consequência do regime ditatorial que vigorou até 1974, apontado também como causa do colossal atraso do país em relação ao resto da Europa, tanto a nível económico como a nível cultural (AR: 69, 169; SM: 94).

A este propósito, é ainda de notar que Osang faz claramente valer o seu conhecimento empírico de residente no Algarve e procura incorporar nos textos uma espécie de manual do quotidiano na região. Assim se compreendem, por exemplo, as longas explicações que Pablo fornece a Lisa sobre os constrangimentos que a introdução de portagens na famosa Via do Infante causou no dia-a-dia dos algarvios, que se viram, em muitos casos, obrigados a deixar de usar essa via rodoviária e a render-se aos congestionamentos da antiga estrada N125, ou ainda os contundentes comentários tecidos acerca dos políticos que, encerrados nos seus gabinetes (por vezes, longe do terreno, na capital), tomam decisões que vão contra o interesse dos cidadãos (AR: 68-69). Estes comentários, facilmente reconhecidos pelo leitor português como dominantes na vox populi, remetem, pois, para a experiência de Osang enquanto residente e profundo conhecedor da região e dos argumentos das suas gentes.

Refira-se ainda que, por um lado, tanto no discurso do narrador como das personagens, o leitor depara com diversos estereótipos tipicamente associados a Portugal, generalizações essas que podem ser lidas como a perspetiva do residente estrangeiro em Portugal, mas também, em vários casos, como eco de opiniões comuns entre os próprios portugueses - em jeito de exemplo, refira-se a visão crítica sobre a ineficácia da justiça e a sua inacessibilidade aos mais desfavorecidos (AR: 123), a lentidão dos serviços nas repartições (AR: 252) ou o elevadíssimo número de funcionários das autarquias (AR: 112).

Por outro lado, é de sublinhar o exercício de desconstrução dos estereótipos que Rolf Osang, como alemão, sabe serem comuns entre os seus conterrâneos acerca de Portugal. Veja-se, por exemplo, o caso de uma tentativa, por parte de Lisa, de subornar um médico, que prontamente lhe responde, ofendido: "Claro. É isso que os estrangeiros pensam sobre nós, que somos uma república das bananas. No caso dos políticos até pode ser verdade, menina, mas não é o caso para milhares e milhares de pessoas decentes neste país" (SM: 75). De igual modo podem ser lidas, a meu ver, as considerações tecidas sobre a crise financeira, que afetou gravemente toda a Europa nos primeiros anos da década passada, com especial impacto em países do Sul, como a Grécia e Portugal. Se, por um lado, Osang dá voz à crítica ao despesismo exemplificado por obras como o Autódromo Internacional do Algarve, frequentemente referido como exemplo da má gestão de dinheiros públicos na região (e no país) (SM: 84), por outro lado, o autor procura mostrar a "outra face da moeda" de uma crise que muitos leitores terão apenas seguido segundo a perspetiva veiculada pelos meios de comunicação social alemães:

O Nuno protestava [... ] sobre a Europa e a conduta financeira do Banco Central, que, na sua opinião, tinha causado mais estragos do que os cidadãos pensavam, pois países pobres como a Grécia ou Portugal, devido à possibilidade de receberem tão facilmente 
Dos Algarves: A Multidisciplinary e-Journal, $37-2020$

[...] tanto dinheiro, se tinham endividado à grande, o que também tinha beneficiado imenso os países ricos e os seus bancos. (SM: 167)

Torna-se assim visível, num exercício de mediação intercultural, a incorporação propositada, por Osang, da voz portuguesa no debate em torno de temas fulcrais na construção da imagem do país junto dos leitores/turistas alemães. É igualmente nesta linha que podem ser lidas as palavras do narrador sobre a vitória no Campeonato Europeu de Futebol de 2016, que dão conta do verdadeiro significado desse feito: "O que se festejou foi muito mais do que apenas a vitória num torneio de futebol. Foi a recuperação de Portugal numa Europa onde, desde a crise financeira, os Portugueses eram representados como dependentes, levianos ou, na realidade, como deveras ingénuos, num continente dominado por uma implacável política financeira." (AR: 263).

Retomando o fio de análise em curso, e nomeadamente o facto de a literatura de turismo se centrar, também, na representação de práticas turísticas e na reflexão sobre essas mesmas práticas, somos encaminhados para novas linhas de leitura dos romances de Osang. Como já apontado anteriormente, nos textos em apreço, a descoberta do Algarve centra-se sobretudo no percurso de Lisa, que percorre a região e os seus recantos, por vezes recônditos, na companhia de personagens locais. A este propósito torna-se especialmente produtivo o cruzamento dos romances com outros textos de Osang, que, como referido acima, não só produziu diversos guias de viagem sobre o Algarve, mas publicou igualmente numerosas crónicas na revista Entdecken Sie Algarve, nas quais se torna visível o desejo de distanciamento do autor em relação às zonas turísticas mais congestionadas. Tal distanciamento evidencia-se na proposta de roteiros por zonas mais remotas do Algarve (como a Foz de Odeleite ou Alcoutim) e do Alentejo (por exemplo, o Pulo do Lobo), muitos dos quais igualmente presentes nos romances (veja-se, por exemplo, Osang 2005b, 2005c, 2007a, 2007b, 2007c, 2007d).

Destaque-se ainda que a ausência de atenção dada aos espaços tradicionalmente associados ao turismo de massas pode ser igualmente lida como uma estratégia portadora de sentido que reforça a clara intenção de afastamento que o guia por detrás dos textos pretende estabelecer em relação a essa prática turística. Não por acaso, Albufeira, um dos polos privilegiados do turismo de massas no Algarve, corresponde a um dos últimos pontos de interesse explorados em pormenor nos romances, já perto do final de Algarve-Rache: "Lisa ainda não conhecia esta grande cidade turística. Isso tinha a ver com o facto de que Albufeira tinha entretanto ganho uma certa fama parecida com a de El Arenal, em Maiorca, com o seu Ballermann, que aqui se chamava The Strip" (AR: 235). As associações a espaços de lazer sobejamente conhecidos entre os alemães como ícones do turismo assente no consumo excessivo de bebidas alcoólicas vão ao encontro desta mesma leitura.

Contudo, mesmo em Albufeira, Lisa deambula, na companhia de Moa, pelas pitorescas e labirínticas ruas do centro da cidade, fazendo o seu percurso à margem dos complexos turísticos que por ali abundam: "Lisa sorria alegremente. Que aquele gigantesco centro turístico rodeado de enormes resorts, onde no pico do verão ficavam hospedadas dezenas de milhares de pessoas, tivesse para oferecer, mesmo no seu centro histórico, um cantinho idílico tão acolhedor era algo de que ela não estava nada à espera." (AR: 237). O exercício de busca de espaços de escape ao excessivo bulício turístico é, pois, reiteradamente incorporado nos romances; ainda a este propósito, leia-se outro exemplo: “Do jardim do 
castelo desceram a Calçada da Galeria até à Praça da República, de onde sai uma imponente ponte romana de sete arcos que atravessa o rio Gilão e faz a ligação à parte oriental de Tavira, uma zona muito menos visitada por turistas, repleta de praças e travessas meio escondidas, envoltas por uma melancolia típica da cidade" (AR: 71-72).

Além do turismo de massas, é de salientar que nos romances é igualmente representado, ainda que a distância, um turismo de elite, patente na pontual descrição de espaços como o luxuoso resort Vila Vita, apresentado como um "templo gourmet sobre falésias atlânticas [...], no qual gente endinheirada de todos os cantos do mundo faz férias. Entre eles estrelas e políticos mundialmente famosos" (SM: 28). No mesmo contexto podem ser consideradas as referências ao "Golden Triangle", entre Almancil, Vale do Lobo e Quinta do Lago (AR: 119), ou às casas luxuosas ao longo da costa do concelho de Lagoa, que, no entanto, como comenta Moa, não pertencem, na sua grande maioria, a portugueses (AR: 81). A menção deste tipo de turismo remete para outra dimensão da construção da imagem do Algarve, desta vez junto de um mercado internacional de nicho, que vê na descontração e na tranquilidade da vida portuguesa os elementos necessários para o desfrute, num anonimato libertador, dos prazeres que a região proporciona (AR: 79). O autor inclui, desta forma, nos romances, dados sobre a configuração de um universo exclusivo que conhece, conferindo destaque à ideia de que o Algarve constitui um destino popular entre personalidades de vários países que, no entanto, passam despercebidas na região: como afirma Pablo, "[... ] o Algarve não é desconhecido. Londres, Dublim, Bruxelas, Munique e Amesterdão fazem férias aqui, não a gente comum, mas sim os influenciadores da opinião pública. Há aqui muito mais individualidades do que tu podes imaginar - todos os dias nos apercebemos disso na galeria." (SM: 99).

A referência, por Pablo, ao espaço Arte Algarve, indissociável da experiência do próprio autor, aponta para uma outra dimensão da reflexão crítica que nos romances é proposta acerca da região, onde o turismo e a cultura, especialmente a arte, se configuram como mundos lamentavelmente afastados. Pablo, como porta-voz do autor, afirma: "[... ] aqui não se está à espera de arte e cultura. Tem a ver com uma imagem distorcida do Algarve. Não se liga esta região a um estilo de vida requintado, mas apenas a praia, areia, sol, golfe, dinheiro, e somente isso. Muito diferente do que se passa no Sul de França ou até mesmo na Toscana." (SM: 93). Neste contexto, creio que não só a galeria a que Pablo se refere no romance mas também os já referidos projetos artísticos do autor podem ser lidos como uma tentativa de intervenção nas práticas turísticas dominantes na região: por um lado, pela forma como nesses projetos se promove a otimização da arte enquanto elemento de diversificação da prática turística dominante assente no turismo de sol e praia; por outro lado, na forma como se procura expandir os cenários turísticos da região, deslocando iniciativas culturais para espaços, por vezes, longe da orla costeira e, em última análise, pelo modo como tais projetos podem servir, igualmente, de polo de aproximação entre a comunidade local e uma comunidade internacional plural, bem conhecida do autor e, em certa medida, também por ele representada.

\section{Considerações finais}

Em conclusão, podemos afirmar que os romances de Rolf Osang constituem, indubitavelmente, exemplos de literatura de turismo. Em primeiro lugar, a aproximação ao género do guia de viagem, motivada sobretudo pela experiência do autor, contribui, 
Dos Algarves: A Multidisciplinary e-Journal, 37 - 2020 certamente, para a forma como nos romances são subtil, ou explicitamente, sugeridos diversos locais a visitar, muitos deles "recantos" afastados das congestionadas zonas da orla costeira. Além disso, neles é promovida a reflexão sobre a cultura local a partir da perspetiva de um residente alemão que, num evidente exercício de mediação intercultural, prepara um “manual do quotidiano" para muitos leitores, também de expressão alemã, com interesse na região. Por fim, destaca-se a reflexão sobre as diferentes formas de prática turística no Algarve, sobre as quais o autor se posiciona claramente nos seus artigos: "Descobrir o Algarve não é ir inúmeras vezes a lugares conhecidos de beleza espetacular, mas, sim, descobrir harmonias escondidas que nos aquecem por dentro. Bem-estar para a alma, abastecer-se de energia na natureza. Nada nos faz melhor." (Osang, 2007d: 16). Torna-se igualmente claro que os estudos em literatura e turismo se configuram como um fértil campo de investigação futura no que diz respeito à análise dos múltiplos textos que, à semelhança dos romances de Osang, se enquadram no fenómeno editorial patente no aumento muito expressivo do número de romances policiais alemães que têm sido publicados sobre Portugal.

\section{Referências}

Cordeiro, M. J. (2010). Olhares alemães: Portugal na literatura turística. Guias de viagem e artigos de imprensa (1980-2006). Lisboa: Colibri.

Cordeiro, M. J. (2013). Der Europa-Diskurs in zeitgenössischen Reisetexten: von H. M. Enzensberger zu Pascal Mercier. In P. Hanenberg e I. Capeloa Gil (Eds.), Der literarische Europa-Diskurs. Festschrift für Paul Michael Lützeler zum 70. Geburtstag (pp. 144-152). Würzburg: Königshausen \& Neumann.

Donn, N. (2018). Visionary Algarve art promoter Rolf Osang dies in Germany. Portugal Resident, 14 de maio. Disponível em: https://www.portugalresident.com/visionary-algarve-art-promoter-rolfosang-dies-in-germanyl

Gaspar, A. (2015). Süßer Mord: Tatort Algarve. Entdecken Sie Algarve, junho de 2015, 30-31.

Gorzelniak, M. (2017). Cônsul da Alemanha em Lagos acha que há potencial no Algarve, mas falta de investimento. Sul Informação. 26 de junho. Disponível em: https://www.sulinformacao.pt/2017/06/consul-da-alemanha-em-lagos-acha-que-ha-potencialno-algarve-mas-falta-de-investimento/.

Neves, M. (2009). Romance Policial. C. Ceia (Coord.), E-Dicionário de Termos Literários. Disponível em: https://edtl.fcsh.unl.pt/encyclopedia/romance-policial/.

Oliveira, T. M. (2018). Mário Lima. Ulyssei@s: Enciclopédia Digital. Disponível em: https://ulysseias.ilcml.com/pt/termo/lima-mario/:pdf=527.

Oliveira, T. M. (2019). Gil Ribeiro. Ulyssei@s: Enciclopédia Digital. Disponível em: https://ulysseias.ilcml.com/pt/termo/ribeiro-gil/.

Osang, R. (2005a). Menschen und Märkte - ESA im Gespräch mit Autor und Galerist Rolf Osang. Entdecken Sie Algarve, janeiro de 2005. Disponível em: https://entdecken-siealgarve.com/archive/0501-mm.

Osang, R. (2005b). Castro Marim, die Salzinsel. Entdecken Sie Algarve, fevereiro de 2005. Disponível em: https://entdecken-sie-algarve.com/land-leute/0502-castro-marim.

Osang, R. (2005c). Alcoutim - Stille Schönheit. Entdecken Sie Algarve, março de 2005. Disponível em: https://entdecken-sie-algarve.com/freizeit/0503-alcoutim.

Osang, R. (2007a). Der Weg ist das Ziel. Entdecken Sie Algarve, janeiro de 2007, 14-17.

Osang, R. (2007b). Von Seeräubern und Sehnsüchten. Entdecken Sie Algarve, junho de 2007, 20-22. 
Osang, R. (2007c). Verborgener Schatz im Herzen der Algarve. Entdecken Sie Algarve, julho de 2007, 22-23.

Osang, R. (2007d). Blaue Oase. Entdecken Sie Algarve, agosto de 2007, 14-16.

Osang, R. (2015). Süßer Mord. Algarve Krimi. Köln: Emons Verlag.

Osang, R. (2017). Algarve-Rache. Kriminalroman. Köln: Emons Verlag.

Osang, R. (2018). Marco Polo Algarve. Ostfildern: Marco Polo.

Osang, R. \& Maeritz, K. (2018). Algarve. Zeit für das Beste. München: Bruckmann Verlag.

Quinteiro, S. \& Baleiro, R. (2019). Estudos em literatura e turismo. Conceitos fundamentais. Lisboa: Centro de Estudos Comparatistas. Disponível em: https://www.academia.edu/39847359/Estudos_em_literatura_e_turismo_Conceitos_funda mentais_2aed.

Reis, C. (2018). Dicionário de estudos narrativos. Coimbra: Almedina.

s.a. (2018, 14 maio). Nachruf Rolf Osang. Entdecken Sie Algarve. Disponível em: https://entdecken-siealgarve.com/nachrichten/nachruf-rolf-osang.

Santos, A. (2004). Ruralidade algarvia. Jornal de Notícias, 26 de agosto. Disponível em: https://www.jn.pt/arquivo/2004/ruralidade-algarvia-457301.html.

Schmitz, J. (2019a). Lost in Fuseta von Gil Ribeiro. Wie aus einem idyllischen Fuseta ein Krimi-Hotspot wurde. Neue Osnabrücker Zeitung, 1 de julho. Disponível em: https://www.noz.de/deutschland-welt/kultur/artikel/1792677/lost-in-fuseta-gil-ribeiro-machtfuseta-zum-krimi-hotspot.

Schmitz, J. (2019b). Der genaue Blick auf Portugal: Algarve-Krimis von Carolina Conrad. Neue Osnabrücker Zeitung, 22 de julho. Disponível em: https://www.noz.de/deutschlandwelt/kultur/artikel/1812215/der-genaue-blick-auf-portugal-algarve-krimis-von-carolina-conrad.

Schmitz, J. (2019c). Carolina Conrad, Mario Lima, Gil Ribeiro: Der Portugal-Krimi boomt. Neue Osnabrücker Zeitung, 12 de agosto. Disponível em: https://www.noz.de/deutschlandwelt/kultur/artikel/1834773/carolina-conrad-mario-lima-gil-ribeiro-portugal-krimi-boomt

Tavares, A. (2018). With more lives than a cat, Porca Preta is now back to its former glory. Portugal Resident, 22 de novembro. Disponível em: https:/www.portugalresident.com/with-morelives-than-a-cat-porca-preta-is-now-back-to-its-former-glory/

Turismo de Portugal (2020). Travel Bl. Alemanha 2020. Caracterização do mercado emissor. Disponível em:https://travelbi.turismodeportugal.pt/ptpt/Documents/Mercados/Alemanha/caraterizacao-do-mercado-emissor-alemanha-2020.pdf.

Vilas-Boas, G. (2020). Carolina Conrad. Ulyssei@s: Enciclopédia Digital. Disponível em: https://ulysseias.ilcml.com/pt/tbaermo/conrad-carolina.

JOÃo RODRIGUES licenciou-se em Línguas e Literaturas Modernas (Estudos Ingleses e Alemães - Ramo de Formação Educacional) na Faculdade de Letras da Universidade de Coimbra, onde concluiu, em 2007, o Mestrado em Estudos Germanísticos. Em 2015, doutorou-se em Estudos Literários, Culturais e Interartísticos na Faculdade de Letras da Universidade do Porto com a apresentação de uma tese sobre a representação da vigilância em romances contemporâneos de expressão inglesa e alemã. Desde 2005, tem lecionado diversas unidades curriculares de Inglês e de Alemão para fins específicos no Instituto Politécnico de Beja, onde desempenha atualmente as funções de Professor Adjunto Convidado. Os seus interesses de investigação incluem os estudos literários e culturais, bem como o ensino de línguas estrangeiras para fins específicos. Endereço institucional: Rua Pedro Soares, Campus do IP Beja, Apartado 6155, 7800-295 Beja, Portugal. 
Dos Algarves: A Multidisciplinary e-Journal, 37-2020

Submetido em 4 de abril de 2020

Aceite em 4 de junho de 2020 